\title{
sciendo
}

DOI: $10.2478 /$ jolace-2021-0008

\section{An exploration of Chinese students' perceived barriers to effective intercultural communication}

\author{
Xiaotian Zhang \& Mingming Zhou \\ University of Macau, China
}

\begin{abstract}
Chinese students nowadays have more opportunities to engage in interactions with people from different cultures, but meanwhile, their performance in authentic intercultural communications may be impeded by a variety of barriers. In this study, we qualitatively explored and summarized various types of barriers of intercultural communication as perceived by 40 Chinese students, based on Rozkwitalska's (2010) model. The findings revealed a series of universal barriers that coincided previous studies (e.g., lack of confidence, shyness, feelings of remoteness, nonproficient use of functional language), and enriched Rozkwitalska's (2010) model with newly identified barriers (e.g., lack of stress tolerance, self-centered communication, protection of face, discrepant performance concerning SES and age). Our study examined intercultural communications in a more comprehensive manner and made an attempt to develop a wellestablished, coherent frame of theory-building in international education research. Practical implications for educators and schools are discussed.
\end{abstract}

Key words: intercultural communication, barriers, intercultural competence

\section{Introduction}

In recent years, China has witnessed a significant growth of students studying internationally. In 2019, around 703,500 Chinese students pursued studies overseas, making China the largest country of origin for international students in the world (Textor, 2021). Along with the increasing opportunities for Chinese young people to get involved in intercultural communication due to globalization and internationalization (Wang, Deardorff, \& Kulich, 2017), research on a wide range of problem areas among Chinese students abroad has been initiated. Henze and Zhu (2012) reviewed existing research on Chinese students studying abroad and observed highly diverse research literature in this field, with such topics as academic culture, learning style, interpersonal communication, psychological adjustment, coping strategies, personal growth, and etc.

During the process of studying abroad, languages and cultures are inevitably exchanged and challenges arise in intercultural communicative encounters. A range of factors have been identified to impede the development of IC, including perceived cultural distance (Rozkwitalska, 2010), shyness and competitiveness (Hawke, Vaccarino, \& Hawke, 2011), language differences (Peltokorpi \& Clausen, 2011), and culture shock (Belford, 2017). As Streitwieser, Le, and Rust (2012) posited, a coherent frame of theory-building has been relatively lacking in international education research, particularly concerning the experience of studying abroad. It is thus necessary to develop a comprehensive framework 
by consolidating the various stumbling blocks to their effective performance in intercultural exchange. The purpose of this study was hence to explore Chinese students' perceptions of factors that hinder effective intercultural communication using a qualitative approach. The findings would allow us to develop a framework which informs scholars and educators in the field of cross-cultural studies of the perceived challenges and obstacles such that corresponding interventions or solutions could be proposed and implemented.

\section{Literature review}

\subsection{Intercultural communication and intercultural competence}

Gudykunst and Kim (2003) conceptualized intercultural communication as "...a transactional, symbolic process involving the attribution of meaning between people from different cultures" (p. 17), which explained how different cultural perceptions and symbolic systems of people could alter their communication practices. Stier (2006) argued that intercultural communication should be analyzed as a complex process, not merely as an encounter. Indeed, the concept of intercultural communication is not confined to communication over language barriers; rather, it includes all types of communication with other cultures (Pergert \& Tiselius, 2020). To ensure effective communication, individuals' ability to behave and communicate effectively and appropriately in intercultural situations is one of the keys. Such an ability is also known as intercultural competence (Deardorff, 2009).

Intercultural competence refers to "the ability to communicate effectively in crosscultural situations and to relate appropriately in a variety of cultural contexts" (Bennett \& Bennett, 2004, p. 149). As Deardorff (2009) maintained, the development of intercultural competence is an ongoing process. Engagement in intercultural communication allows individuals to reflect on and assess the level of their own intercultural competence, which in turn, may improve their intercultural competence. Although intercultural competence has been differently conceptualized within intercultural communication across disciplines, scholars generally reached a consensus on three assumptions (see Leung, Ang, \& Tan, 2014 for a review). First, intercultural competence is an integration of a range of cognitive (knowledge), affective (attitude and motivation), and behavioral skills . Second, the end result of the communication should cover both effectiveness and appropriateness. Third, intercultural competence is universal. It is an ability that individuals can develop without specifying to any culture. Individuals high in intercultural competence are typically (a) more attentive, (b) better able to perceive intercultural signals and adjust their behaviours, (c) more self-monitoring, (d) more empathic, and (e) more effective in intercultural interactions (Chen \& Starosta, 2000).

\subsection{Barriers to intercultural communication: Rozkwitalska's model}

To achieve high levels of intercultural competence is not an easy task. Researchers have identified a range of barriers to intercultural communication which hinder the development of intercultural competence. To name a few, Akhmetshin and others (2017) identified seven types of cross-cultural barriers that arise in the educational environment in the process of intercultural interaction: emotional barriers, phonetic barriers, stylistic 
barriers, intellectual barriers, semantic barriers, motivational barriers, and the barriers initiated by the structure of the group and scheme of creating of interpersonal relations. Azadipour (2019) posited that one's personality types was also an important factor to trace the barriers in cross-cultural learning context. With Chinese samples, Zhu (2020) studied the affective barriers in intercultural communication, and put forward some effective strategies to help communicators enhance their intercultural competence.

One major shortcoming in the past studies is that the barriers were typically treated independently with no interrelations among one another. Given the main aim of this study is to develop a comprehensive framework that delineates the types of barriers during intercultural communication as well as the relationships among these different types, we borrowed Rozkwitalska's (2010) model of cross-cultural interactions and sources of cultural barriers. This model presented a comprehensive set of obstructive factors for effective intercultural communications. The original model was contextualized in crosscultural workplace. We deem it is applicable in most intercultural communication scenarios in educational settings as well, as educational settings share many similarities with workplace. For example, collaborative learning activities and teamwork that require frequent interactions are quite common in today's multicultural classrooms (Elliott \& Reynolds, 2014) and workplaces (Lee \& Bonk, 2014). Further, both a classroom and a company represent a social environment that would either facilitate or hinder communication.

Rooted in major determinants of human actions (Hofstede \& Hofstede, 2007), Rozkwitalska (2010) identified three major categories of barriers influencing interactions between people from different cultures: cultural, individual, and organizational factors. Culturally bounded barriers can influence other communicators' perceptions and attitudes towards them. In this category, misunderstanding between the communicators can easily result in communication breakdown (Korkut, Dolmaci, \& Karaca, 2018), due to the differences in language (del Pino, Higginbottom, 2013), values and standards of behavior (Lifintsev \& Canavilhas, 2017), and ways of thinking (Hawke, Vaccarino, \& Hawke, 2011). Individually rooted barriers can exert a direct impact on individual's behaviors in intercultural scenarios, such as feelings of remoteness (del Pino et al., 2013), low motivation and interest (Peltokorpi \& Clausen, 2011), ethnocentric viewpoints (Keles, 2013), insufficient intercultural knowledge (Lifintsev \& Canavilhas, 2017), stereotypes and inherent shyness (Keles, 2013). Organizational barriers pertain to hierarchical factors within any organization such as inefficient information systems, lack of supervision or training, and other deficiencies in organizational design (Rozkwitalska, 2010). Within institutions, characteristics such as the curriculum design, pedagogy, teacher support, classroom activities and vibes can also become facilitating or hindering factors for students' performance in authentic intercultural interactions. They form boundaries for human actions, which can strengthen the cultural barriers. Using this theoretical framework, the current paper explores the perceived barriers.

\section{Present study}

With the rapid development of the society and economy, Chinese students nowadays have more opportunities to engage in intercultural communications. Peng and colleagues 
(2015) maintained that Chinese students face various difficulties in authentic intercultural communication. According to Wang and others (2010), compared to barriers to communication with distinctly different cultural members (e.g., individualist cultures), some barriers perceived by Chinese students are more easily removed with culturally similar others (e.g., collectivist cultures). Additionally, Chinese students' perceived barriers could differ from students from other cultures due to their particular cultural backgrounds (Xiao \& Petraki, 2007). However, research showed that most college students in China, especially non-English major students, had an inadequate level of competence for effective intercultural communications (Fan, Wu, \& Peng, 2013). Some ascribed their ineffective performance to their inadequate intercultural knowledge and inflexibility in intercultural interactions (Li \& Sun, 2006), and preference of using hint and maladjustment to the western thinking style (Heng, 2018).

To our knowledge, there have been some studies that tapped into barriers to intercultural communication of Chinese students. For example, Holmes (2004) conducted an ethnographic study on Chinese students studying in New Zealand. These students were found not prepared for the dialogic nature of classroom communication, which created difficulties in listening, understanding, and interacting. They also held different expectations of writing styles, and understandings of critical analysis and plagiarism. Xiao and Petraki (2007) examined intercultural communication competence of Chinese students who were studying at an Australian University with questionnaires and interviews. They found that the Chinese students encountered many difficulties when interacting with students from other countries which they ascribed to lack of knowledge of intercultural communication, cultural shock and differences in nonverbal communication and politeness strategies. Gu and Maley (2008) explored the way Chinese students in the UK adapted to their new learning environment. Both Chinese students and their British teachers stressed the need for mutuality of understanding and action. Personal, pedagogical and psychological factors were equally important in influencing the intercultural adaptation process and outcomes. More recently, God and Zhang (2019) investigated how Chinese international students and local students understand and experience intercultural communication in an Australian university. Being restricted by intracultural practices and norms, the students in their study were not able to fully utilise communication techniques to establish common grounds between language and cultural variations via meaning negotiation. This, in return, affected their motivations to have further intercultural interactions.

The above studies revealed various barriers from different angles. However, as Streitwieser et al. (2012) argued, we need a well-established, coherent frame of theorybuilding in international education research, particularly concerning the experience of studying abroad. Rozkwitalska's (2010) model has been applied widely in intercultural communication in workplace. Despite a big overlap with perceived barriers during intercultural communication in educational settings, we expected outstanding types of barriers that could be peculiar to Chinese students. Therefore, our investigation not only built on the findings of previous studies, but also extended past findings with a comprehensive model articulating the sources of cultural barriers to intercultural interactions. By additionally taking Chinese characteristics of interpersonal 
communication (e.g., value of harmony, implicit in expression) into consideration, the present study was expected to examine intercultural communication in a more comprehensive manner.

\section{Methodology}

A qualitative interview method allows us to probe the meaning or underlying reasons of participants' different performances and feelings in intercultural communications $(\mathrm{Qu}$ \& Dumay, 2011). The data was therefore collected through semi-structured interviews which was considered as an effective way to investigate intercultural encounters experienced by individuals (Peltokorpi \& Clausen, 2011).

\subsection{Participants and procedure}

Previous studies on barriers to intercultural communication suggested that a number of 30-60 participants would guarantee the data saturation (del Pino et al., 2013). Eligible participants for this study are those have rich experiences of actual intercultural exchanges and have not undertaken any ICC course or received ICC training. 40 Chinese undergraduate $(n=29)$ and graduate $(n=11)$ students from 23 different universities were recruited using respondent-driven sampling by first reaching out to 1) students majoring in foreign language; and 2) students in overseas study/internship programs. Of these, 20\% of the participants were males, with an average age of 22.55 years ( $S D=1.72$ ). The majors of participants were diverse, including liberal arts degrees such as Education, English, Journalism, and science degrees such as Engineering and Bioengineering. Before the study, consent letters were collected through the participants' willingness to give their responses after being explicitly informed of the nature and purpose of the study. In-depth semistructured interviews about users' intercultural communication experiences, and their perceptions of barriers to effective outcomes were conducted with each participant individually via WeChat (a popular social networking software) using voice call.

The interviews were conducted by the first author following the three steps as suggested by Qu and Dumay (2011). First, we prepared an interview guide outlining questions to be addressed based on Rozkwitalska's (2010) model. Second, we polished the interview guideline by specifying different types of questions used, i.e., direct questions to elicit direct responses (e.g., In your past communications with culturally different others, did you feel your knowledge of of the communicator's culture influence the effectiveness of your communication?); probing questions to draw out more complete narratives (e.g., Could you give a more detailed description of what happened?). Third, we started the interviews while being mindful of all prepared questions as well as necessary interpreting questions (e.g., Is it correct that you feel that [...]?) and throw away questions (e.g., Oh, I forgot to ask you [...]). In order to avoid participants' misunderstanding about the interview questions or obstacles in accurately expressing their ideas, all the interviews were conducted in the participants' mother tongue (Mandarin). All the interviews lasted for 50-80 minutes. The interviews were digitally recorded and transcribed on verbatim. The transcriptions were sent to the participants for confirmation. 


\subsection{Interview guideline}

Our interview guideline was based on the model of cross-cultural interactions and sources of cultural barriers by Rozkwitalska (2010). Interview probes were developed by following the elements depicted in this model. Given that our targets of investigation were university students in China, we adapted the model by replacing organizational factors with institutional factors. Example questions were "Do you tend to be shy/nervous/restless/incoherent when interacting with people from [countries of interviewees' communication partners]?” (Individually rooted factors), "During your past communication with people from [countries of interviewees' communication partners], when you expressed your needs, would you tell the other person directly, or would you try to throw a hint at the other person?" (Culturally bonded barriers), "Did the courses you took and the clubs you joined at your university help you learn about different cultures?" (Institutional factors). Additionally, barriers documented in existing literature that can be mapped to this model were further used to generate interview questions. Questions about participants' past intercultural communication experiences were also solicited. Each of the direct interview question were followed up with probing questions to obtain detailed description or examples of interviewees' experiences, so as to ensure the interview questions are sufficiently in-depth for quality interview responses and analysis (Qu \& Dumay, 2011).

\subsection{Data analysis}

The interviews transcripts were analyzed following Miles and Huberman's (1994) scheme of qualitative data analysis. In both inductive and deductive manners, the authors looked for evidence about the participants' perceived barriers to effective performance in their previous intercultural communications. Based on the structure of the interview guideline, the headings of different dimensions of intercultural competence were first taken as the initial categories (e.g., individually rooted-barriers). Subheadings of the interview guideline was then served as sub-categories (e.g., personality). As the analysis went more in-depth, specific codes were generated according to relevant content that fell into any of the categories. To enhance the validity of the data analysis, the two authors analyzed the data independently and conducted several rounds of discussion comparing the codes and categories on the common highlighted statements, until a final agreement was reached. During the whole process, the authors have also engaged in reflection with continuous self-critique and self-appraisal to minimize the influence of their own experiences on the stages of the research process (Koch \& Harrington, 1998).

\section{Results and discussion}

\subsection{Experiences of intercultural communications}

Before delving into the barriers perceived by our participants, their past intercultural communication experiences were first investigated. As shown in Table 1, participants in the present study encountered culturally different people from different continents in various situations, three major categories were identified as academic study, workplace, and personal life. This evidenced that intercultural dialogues with different degree of cultural distance are now permeating different aspects of everyday life of Chinese 


\begin{tabular}{|c|c|c|}
\hline Category & Specific Occasions & Number \\
\hline \multirow{5}{*}{$\begin{array}{l}\text { Academic } \\
\text { Study }\end{array}$} & Attending courses with classmates from different cultures & $10(25 \%)$ \\
\hline & Attending courses instructed by foreign instructors & $5(12.5 \%)$ \\
\hline & Exchange programs to foreign universities & $5(12.5 \%)$ \\
\hline & Graduate studies supervised by foreign professors & $1(2.5 \%)$ \\
\hline & Research projects with participants from foreign countries & $1(2.5 \%)$ \\
\hline \multirow{3}{*}{ Workplace } & Internships in foreign countries & $13(32.5 \%)$ \\
\hline & Internships in China with foreign colleagues/clients & $6(15 \%)$ \\
\hline & Part-time jobs as an interpreter or a translator & $5(12.5 \%)$ \\
\hline \multirow{2}{*}{ Personal Life } & Friendship/relationship with foreigners & $9(22.5 \%)$ \\
\hline & International trips & $6(15 \%)$ \\
\hline Continents & Cultures of participants' communicatees & Number \\
\hline \multirow{5}{*}{ Africa } & Tanzania & $4(10 \%)$ \\
\hline & Nigeria & $2(5 \%)$ \\
\hline & Egypt & $1(2.5 \%)$ \\
\hline & Kenya & $1(2.5 \%)$ \\
\hline & Madagascar & $1(2.5 \%)$ \\
\hline \multirow[t]{6}{*}{ America } & USA & $25(62.5 \%)$ \\
\hline & Canada & $7(17.5 \%)$ \\
\hline & Brazil & $2(5 \%)$ \\
\hline & Argentina & $1(2.5 \%)$ \\
\hline & Columbia & $1(2.5 \%)$ \\
\hline & Mexico & $1(2.5 \%)$ \\
\hline \multirow[t]{13}{*}{ Asia } & Thailand & $15(37.5 \%)$ \\
\hline & Korea & $7(17.5 \%)$ \\
\hline & Japan & $6(15 \%)$ \\
\hline & Vietnam & $4(10 \%)$ \\
\hline & India & $3(7.5 \%)$ \\
\hline & Cambodia & $2(5 \%)$ \\
\hline & The Philippines & $2(5 \%)$ \\
\hline & Bangladesh & $1(2.5 \%)$ \\
\hline & Israel & $1(2.5 \%)$ \\
\hline & Kazakhstan & $1(2.5 \%)$ \\
\hline & Mongolia & $1(2.5 \%)$ \\
\hline & Nepal & $1(2.5 \%)$ \\
\hline & Pakistan & $1(2.5 \%)$ \\
\hline \multirow[t]{14}{*}{ Europe } & UK & $9(22.5 \%)$ \\
\hline & France & $5(12.5 \%)$ \\
\hline & Germany & $4(10 \%)$ \\
\hline & Russia & $4(10 \%)$ \\
\hline & Ireland & $3(7.5 \%)$ \\
\hline & Italy & $3(7.5 \%)$ \\
\hline & Portugal & $3(7.5 \%)$ \\
\hline & Switzerland & $3(7.5 \%)$ \\
\hline & Spain & $2(5 \%)$ \\
\hline & Austria & $1(2.5 \%)$ \\
\hline & Czech Republic & $1(2.5 \%)$ \\
\hline & Denmark & $1(2.5 \%)$ \\
\hline & Finland & $1(2.5 \%)$ \\
\hline & Norway & $1(2.5 \%)$ \\
\hline \multirow[t]{3}{*}{ Oceania } & Australia & $5(12.5 \%)$ \\
\hline & New Zealand & $1(2.5 \%)$ \\
\hline & Palau & $1(2.5 \%)$ \\
\hline
\end{tabular}

Table 1. Intercultural communications experienced by participants 
students. The increasingly culturally diversified communities in China, the growing opportunities for overseas study, as well as the international connections allowed by technological advancement, have all provided Chinese university students ample opportunities for both abroad and inland intercultural interactions.

\subsection{Culturally bonded barriers to effective intercultural communication}

Seventeen types of barriers in total were identified after in-depth analysis of the interview data. We described the barriers by varying levels as depicted in Rozkwitalska's (2010) model.

5.2.1 National culture: SES, age, listening-centered style of communication, and culture of face

Culture plays a central role in effective communication because it does not only represent the total of shared experiences but also shapes the life experiences of the individuals who occupy a particular culture as members of that community (Nieto, 2010). In our study, culture is also reflected as family culture. Traditional parenting style in China has been variously labeled as "authoritative", "controlling", and "restrictive" (Ang \& Goh, 2006). Such family atmosphere was reported to develop children's internal problems for interpersonal communication as reflected in their self-contained and reserved performance when individual-level power distance appeared between the communicators (Lu \& Chang, 2013). This coincides Bruner's (1990) framework of cultural psychology, which denoted that distinct patterns with cultural differences in individuals' behaviors mainly stemmed from the default strategies which individuals come to rely on in familiar situations. Based on our dataset, the first identified subcategory was concerned with discrepant performance when facing communicators of different social economic status (SES) and age. Thirty-eight participants indicated that the distance between one's own and the other person's SES often result in their reserved and inauthentic self-impression, and the low efficiency of the communication. As some participants recalled, this could largely be ascribed to their self-abasement in front of authority as developed under traditional Chinese parenting style, wherein the children's opinions were often ignored. As some participants reflected, in their past interactions with people with higher SES, they inclined to express ideas in an explicit way, be more tolerant to ideas that out of line with theirs, then hide their real thoughts or beliefs about the topic of concern. For example,

"I am a little bit of fear of power and stuff, even when I disagreed with my student's parent [official of the government], I would say something complimenting on her ideas, and gave up my opinions. She never knows the real me." (Participant 8)

When interacting with culturally dissimilar people of different ages, our participants pointed out that their performance could be different in aspects of the breadth and depth of topics discussed, motivation for and authenticity of information delivery, and tolerance to offensive speech from the communicator. The effectiveness of relevant communication was considered to be lower when communicators were much younger or older than the participants. 
"My culture requires me to respect the elders, those from other cultures are no exception. My attitude of being not so serious, or very tolerant about their messages as right or wrong, invalidated the information I send out." (Participant 40)

Fifteen of the participants related their communication style to the education they received which encouraging an individual to show respect to others by being a good listener, and to stay low-key and modest in communication. Directed by this communication style, participants found themselves could be easily misunderstood by the communicators for being indifferent or weak-minded in giving responses.

"He [colleague] thought I was not interested in the topic he started, but I was just trying to show respect and give him enough room to express his ideas."

(Participant 13)

The notion of face in Chinese culture demonstrates aspects of social image unfolded to others, including one's self-respect, honor, status, reputation, credibility, and competence (Oetzel et al., 2001). The notion of face constitutes the deep mental structure of Chinese people (Liu, 2017). Even in large metropolitan, relatively 'Westernized' cities, face is visible in such scenario as inter- and intra-company communication (Upton-McLaughlin, 2013). As Holmes (2006) observed, this virtue in interpersonal interactions could prompt individuals' frequent face-giving and face-protecting behaviors along with an indirect or listening-centered style of communication. Goffman (1959) illuminated that when individuals foreboded to present an incompetent image of self during communication with others, the face could be saved or protected through restrained performance. As four participants recalled, once they placed much attention on not making fool of themselves during the communication, they would restrain their curiosity for the communicators' cultures, and deliver inauthentic or reduced information.

"Making mistakes in front of others could be humiliating, as my parents taught me, talks more, errors more." (Participant 28)

\subsection{Individually rooted barriers to intercultural communication}

\subsubsection{Personality: Shyness and lack of confidence}

An overwhelming majority of participants (97.5\%) believed that personality of individuals can greatly influenced their performance in intercultural communications. After an intensive recall of the authentic intercultural communications they have experienced before, the participants reported two major personality-related barriers: shyness and lack of confidence. Research on Asian people's intercultural communication showed that sometimes Asian people (e.g., Thai) deliberately appeared to be shy in order to maintain social harmony. Shyness then became a strategic performative behavior which is not a result of external factors or incompetent behavior per se (Vinitwatanakhun, 2019; Chaidaroon, 2003). However, in our dataset, eight participants who perceived themselves as introverted people considered shyness as the largest barrier to intercultural communications. Specifically, when participants felt shy and anxious, they took a negative part in the communication with culturally dissimilar others by spontaneously avoiding any possible verbal communication or cutting down necessary information so as to end the communication as fast as they could. Importantly, an in-depth probing of the 
underlying reasons of the shyness as admitted by these participants indicated that the nonproficient use of the foreign language to communicate greatly fueled their shyness. For example,

“...my focus was not on what other group members were saying, I couldn't help checking whether what I said was correct and polite or not, and that how I missed some important information from them." (Participant 17)

"...but I would definitely do much better and be less shy if I was speaking my mother tongue." (Participant 36)

Lack of confidence is a common problem for individuals speaking another language. The associated anxiety may decrease the chances for conversation (Lin, 2012). People may fear that their low language competence will affect their impression in front of others. Three participants in this study admitted that when they were involved in intercultural communication, their lack of confidence often led them to truncated or unsmooth interactions. This personality trait was particularly linked to underdeveloped skills of using functional language for effective information delivery and reception. For example,

"He [a Japanese driver] might thought I was not interested in their culture, but my reserved responses were just because I was not confident enough in well expressing myself in Japanese." (Participant 10)

\subsubsection{Human nature: Self-absorption in communication}

Nakayama and Martin (2014) critically maintained that how humans can equivalently consider the interests and needs of communicators during communication is limited, as humans are by nature self-centered and egocentric. Previous studies consistently implied that when people ignored the role of intercultural communication as an ego-reduction and self-decentering practice, they seemed more inclined to concern solely or chiefly about one's own interests and needs throughout the communication (Brooks \& Pitts, 2016).

Five participants acknowledged that they could be sometimes self-absorbed in interpersonal communications. They would withdraw their attention from information delivered or queried by other communicators, after they caught the information they intended to obtain in a conversation. In subsequent information exchange, the participants would neglect the information from the others, or merely responded in a perfunctory way. For example,

"My aim in group discussion was to get helpful information to complete my part of the assignment, after that, I easily got distracted and became less talkative." (Participant 29)

\subsubsection{Attitude: Feelings of remoteness}

Hofstede (1980) identified cultural distance as an important stimulus for communicators' uncomfortable feelings with unfamiliarity and uncertainty during intercultural interactions. Gudykunst and Ting-Toomey (1988) asserted a strong impact of such unfamiliarity and uncertainty avoidance on intercultural relationships, denoting that individuals from two cultural extremes would particularly experience a high degree of feeling of remoteness from each other. Such feelings of remoteness caused by cultural 
distance was perceived by sixteen of the participants to hinder their intercultural communications. Our findings coincided previous studies suggesting that the greater the difference between two cultures, the more problems the communicators may encounter in communicating effectively (del Pino et al., 2013; Hawke, Vaccarino, \& Hawke, 2011). Factors that could estrange participants from potential communicators including cultural differences in lifestyle, ways of doing and thinking. This would directly produce misunderstandings, impair individual's motivation for information delivery, and even lead to the deliberate avoidance and other negative emotions of such communication. For example,

"... when I was with classmates from, say, Columbia, I felt at odds more often, did not think we would have much common topics or hobbies, so I was reluctant to hang out with them. Even when the dialogues had to happen, I was not the active one." (Participant 3 )

\subsubsection{Perception: In-group favoritism, prejudices and stereotypes}

In-group favoritism, or ethnocentric viewpoints held by any communicators displaying the pride of one's cultural symbols and values while despising that of the others, can influence all intercultural interactions (Dong, Day, \& Collaço, 2008). As profiled in past studies, the major syndromes of such perceptions (i.e., ingroup solidarity and outgroup hostility) can limit mutual understanding yet breed conflict and avoidance of interaction (Jacobi, 2018; Nameni, 2020). Thirteen participants have perceived the destructive effects of such perceptions on their intercultural communications. According to these participants, it was natural to make comparisons between different cultures during intercultural communication. However, so long as any of the communicators made superior judgement regarding the cultural differences under discussion, the other side(s) would very likely to experience feelings of aversion, and diminished motivation for communication.

“Once he (classmate) believed I was arrogant about my culture, he started to 'beat back' by listing the weaknesses under his impression about my culture. That just made the communication worse." (Participant 39)

Prejudices and stereotypes, as the extension of ethnocentrism, are repeatedly identified obvious barriers to intercultural communication (del Pino et al., 2013). According to Samovar and Porter (1991), intercultural communication can be continually impeded when individuals interpret the behaviour of communicators with unfounded and biased preconceptions to categorize and classify people and situations. Eighteen of the participants reported that their prejudices and stereotypes for communicators generated conflicts, misunderstandings, and uncomfortable feelings during intercultural communications. As the participants commented, such negative outcomes could be of no benefit to eradicate the existing prejudices and stereotypes one had for other cultures.

"I argued with him [classmate] for a long time, but we were not solving the misunderstandings, instead, we brought out more prejudices and stereotypes we had for each other." (Participant 4) 


\subsubsection{Motivation: Lack of motivation for intercultural communication}

Lack of motivation for intercultural communication was often observed in participants' unwillingness to play an active role in initiating communications, or being informative during the communication. This barrier was perceived by eleven participants in their low frequency of information exchange and awkward communication vibes. This is consistent with previous results (Xiao \& Petraki, 2007) indicating that the nature, purpose, and audience of the communication, and the knowledge about the topic could influence the degree of their motivation.

"I was more interested in people from cultures that were quite different from mine, seldom approached those from similar cultures as mine, so when I had to talk to them, I became short-spoken." (Participant 7)

\subsubsection{Knowledge: Insufficient intercultural knowledge}

Wiseman, Hammer, and Nishida (1989) asserted that knowledge of the host and target culture is crucial for an individual to minimize possible misunderstandings, as it proffers important information about the norms and communication rules for communicators to understand each other's behaviors. Intercultural knowledge (i.e., language, dominant values, beliefs, customs, and prevailing ideology), therefore, has been consistently posited to be imperative for effective intercultural communication (God \& Zhang, 2019). Lack of knowledge of individual's own culture and communicator's culture were deemed by thirty-one participants to decrease the effectiveness of their communications with people from different cultures. These participants repeatedly reported their insufficient knowledge about Chinese culture in aspects of politics, history, and religion. When these topics appeared in intercultural communications, they always found it difficult to provide accurate information queried by the communicators.

"I couldn't tell clearly about that historical event of my country, the teacher looked confused, I was quite embarrassed." (Participant 11)

Deficient knowledge about the communicator's culture, as clarified by the participants, incomprehensive or inaccurate understanding of cultural behaviors thwarted active delivery of information, reduced topics and depth of communication, and gave rise to misunderstandings, stereotypes and prejudices.

"I thought he [colleague] had some moral issues when I happened to know he had two wives at the same time. So my attitude was really bad during our first few communications. I later learned that it was actually legal for men to have more than one wife." (Participant 24)

Lack of knowledge in terms of language differences between different cultures was found to boost misunderstandings and lags in responses during communications. This included styles of humor, nonverbal expressions, use of expression symbols in online communication and etc. For example,

"He (language partner) thought I was upset for what he said, but it turned out that I just used the same emoji in his cultural context showing sad feelings to express something funny, as used frequently in my cultural context." (Participant 7) 
Interestingly, although have recognized it as a barrier, few students also considered the lack of intercultural knowledge as potential facilitator for intercultural communication. That is, the lack of knowledge of certain topics may actually create valuable opportunities for promoting the communication, and knowledge construction. For example,

"Just because of the lack of knowledge, there were lots of questions, and questions are good topics for communication." (Participant 15)

\subsubsection{Skills and abilities: Non-proficient use of functional language and lack of} stress tolerance

The fundamental ways in which language can be a barrier to intercultural communication are problems of vocabulary, idiomatic, experiential and conceptual equivalence, especially when communicators do not share a common language (Jandt, 2001). Previous studies have observed individuals' reduced engagement in intercultural communication because of their perceived imperfect command of foreign language (God \& Zhang, 2019). Insufficient linguistic skill, from our research findings, was emphasized by twenty-two participants to be a salient barrier to effective intercultural communication. These participants realized that because they were not well versed in using the functional language for information exchange was problematic more often than not. This paramount basis for further interpretation or decoding of the information was hence ill-established. One participant particularly pointed out, even though he had sufficient intercultural knowledge for proceeding effective communication, language barrier could make the sharing process to be bristled with difficulties.

"The hotel receptionist had to repeat for many times to let me understand what she was trying to say, that had really slowed our communication." (Participant 33)

Communicating with culturally different others generates varying levels of psychological and sociocultural stress requiring adjustment (Barna, 1983). As Redmond and Bunyi (1993) identified, how well an individual was able to tolerate or cope with stress and perform consistently in situations with unforeseen challenges, depended on one's skills for intercultural communication and acculturation (e.g., resilience, language proficiency, cultural knowledge, adaption to different communication styles, etc.). Lack of stress tolerance as a barrier was noted by six participants when the surroundings and topics under discussion made them nervous. In other words, participants' inability for actively coping with stress made their performance out-of-kilter in intercultural communication. This is mainly caused by the intense exposure to stressful environment, or challenging topics that required high concentration and immediate response.

"Sometimes the topics I needed to interpret are complicated and difficult, I made more mistakes than usual as I got more and more nervous and even distracted a bit from what my employer was saying." (Participant 1) 


\subsubsection{Intelligence level: Lack of cultural intelligence}

Cultural intelligence or cultural quotient (CQ) deals with an individual's capability to accurately grasp and reason with cultural concepts, solve problems, and behave effectively in situations characterized by cultural diversity (Ang et al., 2007). As one major dimension of CQ, metacognitive CQ reflects the mental process that individuals use their abilities of planning, monitoring and revising the communication to acquire and understand cultural knowledge (Earley \& Ang, 2003). CQ was found to influence cultural judgement and decision-making during interactions (Rozkwitalska, 2010). Four participants perceived their low metacognitive CQ as a barrier to intercultural communications. In their attempts to monitor and evaluate the process of intercultural communication, these participants found themselves struggling with drawing an accurate and timely conclusion, particularly in terms of the progress and enjoyableness of the current communication. This was also considered to impede individuals to fine-tune the subsequent communication.

"I hesitated a lot on the timing to facilitate or end a topic, as I found it difficult to tell whether the other side had well gotten my message, or whether he or she was offended by any of my words or nonverbal actions." (Participant 25)

\subsection{Organizational barriers to intercultural communication}

5.4.1 Institutional ethnocentrism: Ethnocentric viewpoints concerning school ranking and country's development level

Ethnocentric viewpoints at an institutional level, based on six participants' illustrations, depicted individual's sense of superiority over the communicators regarding the rank of their universities, and their country's level of development. Similar as the way that general ethnocentric perceptions hinder effective intercultural communication, participants would neglect or despise communicator's opinions, and tended to actively express themselves during the communication. As a result, participants were less likely to effectively receive messages delivered by the communicators. Our findings echoed Rozkwitalska's (2010) study in which staffs in transnational corporations perceived their institutional ethnocentric attitudes, on the other hand, enlarged the distance between the communicators, and consequently made the communication unpleasant.

"I thought they [student visitors] might not see as much as we did, so when I talk with them, I always assumed I knew much more than them." (Participant 17)

5.4.2 Cultural characteristics of institutions: Lack of opportunities for intercultural communication

Growing evidence (Eisenchlas \& Trevaskes, 2007; Zhang \& Zhou, 2019) suggests that intercultural communication skills can best be developed through experiential learning, wherein knowledge is created through individuals' grasp and transformation of experiences during frequent exposure to different cultures. However, the majority of participants in this study did not have much experience in cross-cultural communication due to the cultural characteristics of their universities. As Lough (2011) noted, sufficient opportunities for intercultural integration can facilitate the understanding and acceptance of different cultures. Lack of opportunities for authentic intercultural 
communication in universities, according to eight participants, would generate gaps between the intercultural knowledge and skills they acquired from relevant courses or textbooks, and the expected effective performance in authentic intercultural communications. From their points of view, frequent intercultural contacts during college years would offer students ample opportunities to validate the authenticity of theoretical knowledge they learned in classroom.

"If I had more opportunities to get along with international students before my internship, I believe I could perform better in later real intercultural communication I encountered....." (Participant 29)

\section{Conclusions and implications}

In this study, we explored and summarized various types of barriers of intercultural communication as perceived by Chinese students, based on Rozkwitalska's (2010) model (see Figure 1).

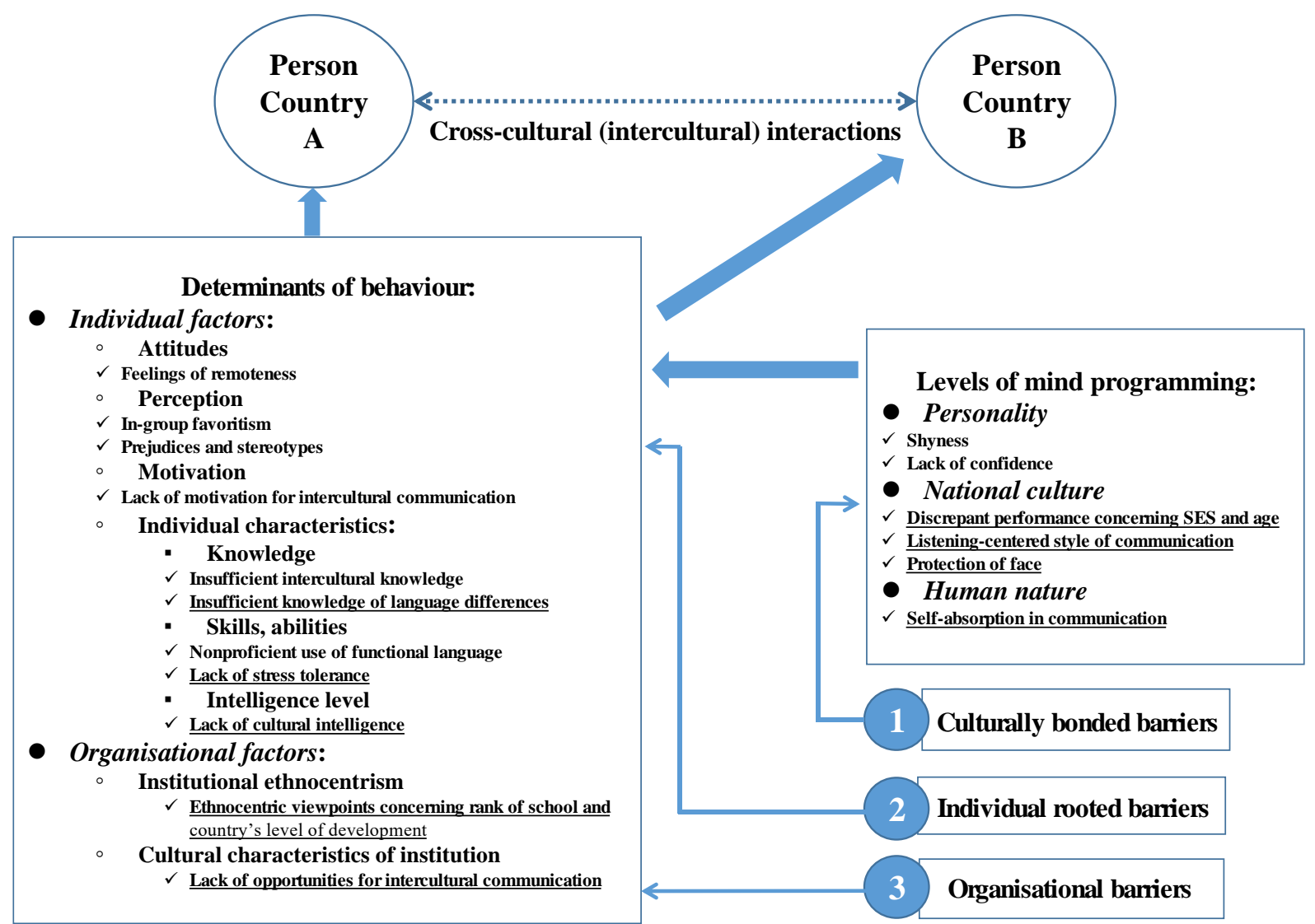

Fig. 1: Model of cultural barriers during intercultural interactions. (The underlined categories were newly added based on the current study.) Source: Rozkwitalska, 2010, Chapter 2.1, Figure 2.1 (Permission obtained from the author).

A unique contribution of this study is the enrichment of Rozkwitalska's model by the emergence of new subcategories as reflected by our data. Specifically, the 17 types of barriers include: personality (i.e., shyness, sensitivity, lack of confidence), culturally 
bonded barriers (i.e., discrepant performance concerning SES and age, listening-centered style of communication, protection of face), human nature (i.e., self-absorption in communication), attitudes (i.e., feelings of remoteness), perception (i.e., ethnocentric viewpoints, prejudices and stereotypes), motivation (i.e., lack of motivation), knowledge (i.e., insufficient intercultural knowledge, insufficient knowledge of language differences), skills and abilities (i.e., nonproficient use of functional language, lack of stress tolerance), intelligence level (lack of cultural intelligence), institutional ethnocentrism (i.e., ethnocentric viewpoints concerning school ranking and country's level of development), and cultural characteristics of institution (i.e., lack of opportunities for intercultural communication).

Massive efforts made by scholars in this field undoubtedly advanced the development of assessment tool of and intervening practice for improving intercultural competence (Deardorff \& Arasaratnam-Smith, 2017). Considering the influence of individually and culturally rooted factors as discussed in previous sections, however, the real-world faceto-face or online intercultural situations can often bring individuals unpredictable challenges (Logan, Steel, \& Hunt, 2015). It is therefore unlikely for researchers and practitioners to rely on one-size-fits-all tools to meet the various needs of individuals from different cultures. We hereby argue that it is of equal importance to identify individuals' perceived barriers, with and without specific cultural characteristics, in the authentic intercultural encounters. These identified barriers are believed to provide a fuller picture for researchers who aim at developing effective tools to assess intercultural competence of, and to identify hindering factors to effective intercultural communication perceived by individuals with similar cultural background as our participants.

Important implications can also be drawn from our findings for educators and schools. For educators, a deeper understanding of potential barriers that students may experience in authentic intercultural communication, can help teachers to equip learners with needed intercultural communication skills through effective pedagogical design to avoid such barriers, as well as to understand communicators' culturally bonded barriers with a decent level of dissimilarity openness (Lloyd \& Härtel, 2003). For schools, it appears to be important for curriculum designers to avail ample opportunities for optimal development to learners' intercultural communication competence, by integrating real-life intercultural communications into textbook-based teaching. As such, learners will be able to consolidate and authenticate the knowledge they have learned during personal engagement in intercultural communications. As suggested by researchers, such intercultural links can be effectively established using mobile technology in nowadays classrooms in forms of peer or group collaborative learning (Mittelmeier et al., 2018).

A few limitations of this study need to be noted. First, participants of this study included only Chinese university students, the identified barriers to their past intercultural communications may limit the findings to be generalized to other cultural groups, especially for members from individualist cultures. Our findings, instead, allow future comparative studies to identify possible similarities of and differences between barriers to effective intercultural communications from a cross-cultural perspective. Second, most barriers as reported by our participants were based on their face-to-face intercultural communication experiences which required more immediate reactions. Given the high 
percentage of Chinese university students who are on social media platforms in the age of connectivity, it is therefore necessary for future studies to investigate or compare possible barriers in different platforms for intercultural communication, such as digital platform that may ease the information exchange (Balvin \& Tyler, 2006). Third, the overwhelming majority of participants in this study were females, this could leave gender bias to our results. Future research with similar purpose is hence suggested to take gender differences into consideration. Fourth, due to the limited labor and time, this study failed to scrutinize the roles that the context of communication, participants' gender, SES, and other demographic variables play in shaping their own perceptions of these IC interactions. Future studies are thus encouraged to take these factors into account and compare individuals' perceptions of their performance in both one-off meeting and regular interactions.

\section{Declaration}

The authors declare that they have no conflict of interest.

\section{References}

Akhmetshin, E. M., Makulov, S. I., Talysheva, I. A., Fedorova, S. Y., \& Gubarkov, S. (2017). Overcoming of intercultural barriers in the educational environment. Man in India, 97(15), 281-288.

Ang, R. P., \& Goh, D. H. (2006). Authoritarian parenting style in Asian societies: A clusteranalytic investigation. Contemporary Family Therapy, 28(1), 131-151. https://doi.org/10.1007/s10591-006-9699-y

Ang, S., Van Dyne, L., Koh, C., Ng, K. Y., Templer, K. J., Tay, C., \& Chandrasekar, N. A. (2007). Cultural intelligence: Its measurement and effects on cultural judgment and decision making, cultural adaptation and task performance. Management and Organization Review, 3(3), 335-371. https://doi.org/10.1111/j.1740-8784.2007.00082.x

Azadipour, S. (2019). Personality types and intercultural competence of foreign language learners in education context. Journal of Education and Health Promotion, 8, 1-8. https://doi.org/10.4103/jehp.jehp44718

Balvin, N., \& Tyler, M. C. (2006). Emotions in cyberspace: The advantages and disadvantages of online communication. Organisational Psychologist, 5-8.

Barna, L. (1983). The stress factor in intercultural relations. In D. Landis \& R. W. Brislin (Eds.), Handbook of intercultural training volume 2: Issues in training methodology (pp. 19-49). Pergamon Press.

Belford, N. (2017). International students from Melbourne describing their cross-cultural transitions experiences: Culture shock, social interaction, and friendship development. Journal of International Students, 7(3), 499-521.

https://doi.org/10.32674/jis.v7i3.206

Bennett, J. M., \& Bennett, M. J. (2004). Developing intercultural sensitivity: An integrative approach to global and domestic diversity. In D. Landis, J. Bennett \& M. Bennett (Eds.), Handbook of intercultural training (3rd ed., pp. 147-165). Sage.

Brooks, C. F., \& Pitts, M. J. (2016). Communication and identity management in a globallyconnected classroom: An online international and intercultural learning experience. Journal of International and Intercultural Communication, 9(1), 52-68. https://doi.org/10.1080/17513057.2016.1120849

Bruner, J. S. (1990). Acts of meaning. Harvard University Press. 
Chaidaroon, S. (2003). When shyness is not incompetence: A case of Thai communication competence. Intercultural Communication Studies, 12(4), 195-208.

Chen, G. M., \& Starosta, W. J. (2000). The development and validation of the Intercultural Sensitivity Scale. Human Communication, 3, 1-15.

Deardorff, D. K. (2009). The SAGE handbook of intercultural competence. Sage.

Deardorff, D. K., \& Arasaratnam-Smith, L. A. (2017). Intercultural competence in higher education: International approaches, assessment and application. Routledge.

del Pino, F. J. P., Soriano, E., \& Higginbottom, G. M. (2013). Sociocultural and linguistic boundaries influencing intercultural communication between nurses and Moroccan patients in southern Spain: A focused ethnography. BMC Nursing, 12(1), 14-22. https://doi.org/10.1186/1472-6955-12-14

Dong, Q., Day, K. D., \& Collaço, C. M. (2008). Overcoming ethnocentrism through developing intercultural communication sensitivity and multiculturalism. Human Communication, 11(1), 27-38.

Earley, P. C., \& Ang, S. (2003). Cultural intelligence: Individual interactions across cultures. Stanford University Press.

Eisenchlas, S., \& Trevaskes, S. (2007). Developing intercultural communication skills through intergroup interaction. Intercultural Education, 18(5), 413-425. https://doi.org/10.1080/14675980701685271

Elliott, C. J., \& Reynolds, M. (2014). Participative pedagogies, group work and the international classroom: An account of students' and tutors' experiences. Studies in Higher Education, 39(2), 307-320. https://doi.org/10.1080/03075079.2012.709492

Fan, W. W., Wu, W. P., \& Peng, R. Z. (2013). A survey on self-evaluation of Chinese college students' intercultural competence. Chinese Foreign Language, 6, 53-59.

God, Y. T., \& Zhang, H. (2019). Intercultural challenges, intracultural practices: How Chinese and Australian students understand and experience intercultural communication at an Australian university. Higher Education, 78(2), 305-322. https://doi.org/10.1007/s10734-018-0344-0

Goffman, E. (1959). The presentation of self in everyday life. Doubleday.

Gu, Q., \& Maley, A. (2008). Changing places: A study of Chinese students in the UK. Language and Intercultural Communication, 8(4), 224-245. https://doi.org/10.1080/14708470802303025

Gudykunst, W. B., \& Kim. Y. Y. (2003). Communicating with strangers: An approach to intercultural communication. McGraw-Hill.

Gudykunst, W. B., \& Ting-Toomey, S. (1988). Culture and interpersonal communication. Sage.

Hawke, F. V., Vaccarino, F., \& Hawke, E. (2011). How you doing, mate? The perceptions of benefits and barriers in forming friendships with international students: A New Zealand perspective. Intercultural Communication Studies, 20(2), 177-189.

Heng, T. T. (2018). Different is not deficient: Contradicting stereotypes of Chinese international students in US higher education. Studies in Higher Education, 43(1), 2236. https://doi.org/10.1080/03075079.2016.1152466

Henze, J., \& Zhu, J. (2012). Current research on Chinese students studying abroad. Research in Comparative and International Education, 7(1), 90-104. https://doi.org/10.2304/rcie.2012.7.1.90

Higginbottom, G. (2013). Sociocultural and linguistic boundaries influencing intercultural communication between nurses and Moroccan patients in southern Spain: A focused ethnography. BMC Nursing, 12(1), 14-21. https://doi.org/10.1186/1472-6955-12-14 
Hofstede, G. (1980). Culture's consequences: International differences in work-related values. Sage Publications.

Hofstede, G., \& Hofstede, G. J. (2007). Kultury i organizacje. PWE.

Holmes, P. (2004). Negotiating differences in learning and intercultural communication: Ethnic Chinese students in a New Zealand university. Business Communication Quarterly, 67(3), 294-307. https://doi.org/10.1177/1080569904268141

Holmes, P. (2006). Problematising intercultural communication competence in the pluricultural classroom: Chinese students in a New Zealand university. Language and Intercultural Communication, 6(1), 18-34. https://doi.org/10.1080/14708470608668906

Jacobi, L. (2018). Ethnocentric attitudes of American and international students: Assessing the impact of collaboration. Journal of Intercultural Communication Research, 47(6), 530-544. https://doi.org/10.1080/17475759.2018.1506352 Jandt, F. E. (2001). Intercultural communication: An introduction. Sage.

Keles, Y. (2013). What intercultural communication barriers do exchange students of Erasmus Program have during their stay in Turkey, Mugla?. Procedia-Social and Behavioral Sciences, 70, 1513-1524. https://doi.org/10.1016/j.sbspro.2013.01.219

Koch, T., \& Harrington, A. (1998). Reconceptualizing rigour: The case for reflexivity. Journal of Advanced Nursing, 28(4), 882-890. https://doi.org/10.1046/j.13652648.1998.00725.x

Korkut, P., Dolmaci, M., \& Karaca, B. (2018). A study on communication breakdowns: Sources of misunderstanding in a cross-cultural setting. Eurasian Journal of Educational Research, 18(78), 139-158. https://doi.org/10.14689/ejer.2018.78.7

Lee, H., \& Bonk, C. J. (2014). Collaborative learning in the workplace: Practical issues and concerns. International Journal of Advanced Corporate Learning, 7(2), 10-17. https://doi.org/10.3991/ijac.v7i2.3850

Leung, K., Ang, S., \& Tan, M. L. (2014). Intercultural competence. Annual Review of Organizational Psychology and Organizational Behavior, 1(1), 489-519. https://doi.org/10.1146/annurev-orgpsych-031413-091229

Li, C. Y., \& Sun, Y. N. (2006). An analysis of student volunteers' intercultural communicative competence at international conference. Journal of Suzhou University, $5,21-23$.

Lifintsev, D. S., \& Canavilhas, J. (2017). Cross-cultural management: Obstacles for effective cooperation in multicultural environment. Scientific Bulletin of Polissia, 2(10), 195-202. https://doi.org/10.25140/2410-9576-2017-2-2(10)-195-202

Lin, Y. (2012). Chinese international students' intercultural communication competence and intercultural communication apprehension in the USA [Unpublished doctoral dissertation]. East Tennessee State University.

Liu, J. (2017). Face culture and Chinese family moral education. Moral Education China, 3, 16-20.

Lloyd, S. \& Härtel, E. J. (2003). The intercultural competencies required for inclusive and effective culturally diverse work teams. Monash Univeristy.

Logan, S., Steel, Z., \& Hunt, C. (2015). Investigating the effect of anxiety, uncertainty and ethnocentrism on willingness to interact in an intercultural communication. Journal of Cross-Cultural Psychology, 46(1), 39-52. https://doi.org/10.1177/0022022114555762

Lough, B. J. (2011). International volunteers' perceptions of intercultural competence. International Journal of Intercultural Relations, 35(4), 452-464. https://doi.org/10.1016/j.ijintrel.2010.06.002 
Lu, H. J., \& Chang, L. (2013). Parenting and socialization of only children in urban China: An example of authoritative parenting. The Journal of Genetic Psychology, 174(3), 335343. https://doi.org/10.1080/00221325.2012.681325

Miles, M. B., \& Huberman, A. M. (1994). Qualitative data analysis: An expanded sourcebook. Sage.

Mittelmeier, J., Rienties, B., Tempelaar, D., Hillaire, G., \& Whitelock, D. (2018). The influence of internationalised versus local content on online intercultural collaboration in groups: A randomised control trial study in a statistics course. Computers \& Education, 118, 82-95. https://doi.org/10.1016/j.compedu.2017.11.003

Nakayama, T., \& Martin, J. (2014). Ethical issues in intercultural communication competence: A dialectical approach. In X. D. Dai \& G. M. Chen (Eds.), Intercultural communication competence: Conceptualization and its development in cultural contexts and interactions (pp. 97-117). Cambridge Scholars.

Nameni, A. (2020). Research into ethnocentrism and intercultural willingness to communicate of Iraqi and Iranian medical students in Iran. Journal of Intercultural Communication Research, 49(1), 61-85. https://doi.org/10.1080/17475759.2019.1708430

Nieto, S. (2010). Understanding multicultural education in a sociopolitical context. In S. Nieto (Ed.), Language, culture, and teaching: Critical perspectives (pp. 38-65). Routledge.

Oetzel, J., Ting-Toomey, S., Masumoto, T., Yokochi, Y., Pan, X., Takai, J., \& Wilcox, R. (2001). Face and facework in conflict: A cross-cultural comparison of China, Germany, Japan, and the United States. Communication Monographs, 68(3), 235-258. https://doi.org/10.1080/03637750128061

Peltokorpi, V., \& Clausen, L. (2011). Linguistic and cultural barriers to intercultural communication in foreign subsidiaries. Asian Business \& Management, 10(4), 509-528. https://doi.org/10.1057/abm.2011.20

Peng, R. Z., Wu, W. P., \& Fan, W. W. (2015). A comprehensive evaluation of Chinese college students' intercultural competence. International Journal of Intercultural Relations, 47, 143-157. https://doi.org/10.1016/j.ijintrel.2015.04.003

Pergert, P., \& Tiselius, E. (2020). Intercultural competence and communication over language barriers. In K. A. Mazur \& S. L. Berg (Eds.), Ethical Issues in Pediatric Hematology/Oncology (pp. 203-222). Cham.

Qu, S. Q., \& Dumay, J. (2011). The qualitative research interview. Qualitative Research in Accounting \& Management, 8(3), 238-264. https://doi.org/10.1108/11766091111162070

Redmond, M. V., \& Bunyi, J. M. (1993). The relationship of intercultural communication competence with stress and the handling of stress as reported by international students. International Journal of Intercultural Relations, 17(2), 235-254. https://doi.org/10.1016/0147-1767(93)90027-6

Rozkwitalska, M. (2010). Barriers of cross-cultural communication according to the research findings. Journal of Intercultural Management, 2(2), 37-52.

Samovar, L. A., \& Porter, R. E. (1991). Communication between cultures. Wadsworth.

Stier, J. (2006). Internationalisation, intercultural communication and intercultural competence. Journal of Intercultural Communication, 11, 1-12.

Streitwieser, B. T., Le, E., \& Rust, V. (2012). Research on study abroad, mobility, and student exchange in comparative education scholarship. Research in Comparative and International Education, 7(1), 5-19. https://doi.org/10.31235/osf.io/zc459 
Textor, C. (2021). Number of students from China going abroad for study from 2009 to 2019. Retrieved from https://www.statista.com/statistics/227240/number-ofchinese-students-that-study-abroad/

Upton-McLaughlin, S. (2013). Gaining and losing face in China. The China Culture Corner. Retrieved from https://chinaculturecorner.com/2013/10/10/face-in-chinesebusiness/

Vinitwatanakhun, A. (2019). Shyness and language achievement in a Thai EFL context. Language and Communication in the Era Glocalization, 80, 85-92.

Wang, S., Sun, X., \& Liu, C. (2010). Intercultural analysis of communication anxieties encountered by international students in the United States. Intercultural Communication Studies, 19(2), 217-234.

Wang, Y. A., Deardorff, D. K., \& Kulich, S. J. (2017). Chinese perspectives on intercultural competence in international higher education. In D. K. Deardorff \& L. A. ArasaratnamSmith (Eds.), Intercultural competence in higher education: International approaches, assessment and application (pp. 95-109). Routledge.

Wiseman, R. L., Hammer, M. R., \& Nishida, H. (1989). Predictors of intercultural communication competence. International Journal of Intercultural Relations, 13(3), 349-370. https://doi.org/10.1016/0147-1767(89)90017-5

Xiao, H., \& Petraki, E. (2007). An investigation of Chinese students' difficulties in intercultural communication and its role in ELT. Journal of Intercultural Communication, 13(2), 66-78.

Zhang, X., \& Zhou, M. (2019). Interventions to promote learners' intercultural competence: A meta-analysis. International Journal of Intercultural Relations, 71, 31 47. https://doi.org/10.1016/j.ijintrel.2019.04.006

Zhu, S. (2020). A study on affective barriers in intercultural communication and related strategies. Theory and Practice in Language Studies, 10(12), 1651-1655. https://doi.org/10.17507/tpls.1012.20

\section{Contact:}

Xiaotian Zhang

Faculty of Education

University of Macau

Av. Padre Tomas Pereira

Taipa, Macau

SAR, China

e-mail: mollyzhangxt@163.com 